\author{
Available online at https://www.rjtl.org \\ Volume:1, Issue:3, 64-65, 2020 \\ ISSN: $2708-3632$ \\ DOI: https://doi.org/10.46590/rjtl.2020.010302
}

\title{
An Experimental Study on Protective Gloves Used in Pakistan.
}

\author{
Beena Zehra* , Hafiz Rub Nawaz, Barkat Ali Solangi, Uzma Nadeem and Mohammad Zeeshan \\ Leather Research Centre, PCSIR, D-102, South Avenue, SITE, Karachi, Pakistan.
}

Paper History

Received : October 2020

Accepted : November 2020

Published : November 2020

Corresponding Author

Beena Zehra

zehrabeena@yahoo.com

\begin{abstract}
This technical study deals with the experimental evaluation of four different safety gloves, used in Pakistan for protection of hands. The samples were prepared and tested according to their standard test methods EN-388. The samples for EN388 were subjected to three physical tests; puncture resistance $(\mathrm{N})$, abrasion resistance (cycles), tear resistance $(\mathrm{N})$. The results revealed that the performance levels of synthetic leather/ PVC gloves were found higher than other gloves.
\end{abstract}

Keywords: Comparison,Physical Testing, Protective Gloves.

Citation: Beena Zehra*, Hafiz Rub Nawaz, Barkat Ali Solangi, Uzma Nadeem and Mohammad Zeeshan, An Experimental Study on Protective Gloves Used in Pakistan.. Research Journal of Textile and Leather, 1(3), 64-65, 2020.

\section{INTRODUCTION}

The protective gloves are used for the protection of hands at work places such as any type of mechanical/chemical risks safety. These gloves are being made from different synthetic materials or polymers. The synthetic rubber, polymers, textile fibres, synthetic leather fibres, and several other polymeric materials are used in the manufacturing of gloves [1].

The selection of appropriate gloves is a customer demand according to use internationally. No significant work has been found on evaluation of protective gloves. Although, the differences in the mechanical behavior between the manufacturers and glove materials types has been reported earlier studies [2-5]. Therefore, this study aimed to evaluate the performance level of different gloves samples which are being currently prepared in Pakistan.

\section{MATERIAL AND METHODS}

Four types of leather gloves were selected for evaluation in this study as mentioned in table 1.The samples were tested according to Method EN:388. European EN 388 standard is designed to evaluate the performance of a fabric or layers of fabric for their ability to resist rubbing by weights , cutting by a blade or sharp object, tearing resistance, and puncture by a pointed object. The brief of three methods which were used in this study given below.

\subsection{Abrasion Resistance}

The sample is subjected to abrasion with sandpaper by a determined pressure. The protection level is awarded on a scale of 1 to 4 depending on the number of turns required until a break appears in the sample.

\subsection{Tearing Strength}

The force required to tear the glove material separately is measured. The performance level is indicated by a number between 1 and 4 based on tearing force.

\subsection{Puncture Resistance}

This test is required to measure the force to puncture the material with a tip. The performance level is between 1 and 4 , where 4 indicates the strongest material.

\section{RESULTS AND DISCUSSION}

In this study, four different glove samples were collected from different exporters used in Pakistan and tested according to the standard method as described in material and methods. According to European Union Standard a protective glove against mechanical risks shall have a performance level of 1 or above for at least one of the properties i-e abrasion, tear and puncture for assigning of level as per performance results against each property [6].

The two categories are being used for the selection of gloves. The category 1 is usually used for the common house hold gloves for cleaning purpose while the category 2 is used for the protection of hands from mechanical risks for independents. The performance level for category 2 required at least following levels; the abrasion resistance min level 2, 
blade cut resistance min level 1 , puncture resistance min level 2, tear resistance min level 2 . We have performed three tests for EN 388 for all samples as shown in table 2 .

Table 1. Selected Samples Description

\begin{tabular}{|c|c|c|c|c|}
\hline \multirow[t]{2}{*}{ Sample } & \multicolumn{4}{|c|}{ Sample description/Material Used } \\
\hline & \multicolumn{4}{|c|}{ Black colour Artificial leather Cirino (Polyester) } \\
\hline \multirow{3}{*}{ Leather glove } & \multicolumn{4}{|c|}{ Palm side: Black Colour Artificial Leather } \\
\hline & \multicolumn{4}{|c|}{ Back Side : black colour Polyester fabric } \\
\hline & & \multicolumn{3}{|c|}{ Wrist: Velcro closure } \\
\hline \multicolumn{2}{|c|}{$\begin{array}{l}\text { High Impact Protection Mechanical } \\
\text { glove }\end{array}$} & \multicolumn{3}{|c|}{ PVC grip material /Kelvar /HiViz spandex/ Thermo plastic Rubber } \\
\hline \multirow{3}{*}{\multicolumn{2}{|c|}{ Motor cycle Gloves }} & \multicolumn{3}{|c|}{ Palm : Brown color Artificial leather (polyester) } \\
\hline & & \multicolumn{3}{|c|}{ Back side: Black color Lycra Polyester fabric } \\
\hline & & \multicolumn{3}{|c|}{ Wrist : Velcro closure } \\
\hline \multicolumn{2}{|c|}{$\begin{array}{l}\text { High Impact Protection Mechanical } \\
\text { glove }\end{array}$} & \multicolumn{3}{|c|}{$\begin{array}{l}\text { Synthetic Leather/PVC grip /Kelvar /HiViz spandex/ Thermo plastic } \\
\text { Rubber }\end{array}$} \\
\hline \multicolumn{5}{|c|}{ Table 2: Results of Protective Gloves (EN 388:2003): EN 388:2016(EN 13594:2015) } \\
\hline Sample & \multicolumn{2}{|c|}{ Puncture Resistance (N) } & Abrasion Resistance (cycles) & Tear Resistance $(\mathrm{N})$ \\
\hline Sample 1 & \multicolumn{2}{|c|}{$40.08+5.26($ level 1$)$} & Break at 750cycles(level 2) & $52.16 \pm 1.66$ (level 3) \\
\hline Sample 2 & \multicolumn{2}{|c|}{$45.35 \pm 6.96($ level1 $)$} & Break at 3940 cycles(level 3) & $106.37 \pm 1.20($ level 4$)$ \\
\hline Sample 3 & \multicolumn{2}{|c|}{$46.66 \pm 2.96$ ( level 1) } & Break at 1137 cycles(level 2) & $65.83 \pm 2.30($ level 3$)$ \\
\hline Sample 4 & \multicolumn{2}{|c|}{$38.98+5.08($ level1) } & Break at 4000 cycles(level3) & $104.79 \pm 2.10($ level 4$)$ \\
\hline
\end{tabular}

The results proved that the highest abrasion was observed in sample four which was synthetic leather/PVC glove. The PVC or synthetic glove shown lower puncture values as compare to other samples PVC is a thermoplastic polymer and does not shown tactile property. The differences in all three tests was observed which is due to the change of gloves materials. These results suggests that the selection of glove samples varied from material to material. However, the performance level for category 2 required at least following levels; the abrasion resistance min level 2, puncture resistance min level 2, tear resistance min level 2.

\section{CONCLUSIONS}

Although, this study is very limited but it will be helpful for various gloves users to literate about basic knowledge. The efficiency of glove is varied from sample to sample. The selection of material of glove is important according to specific use. The quality of a glove directly related to the manufacturer of glove basic material. Each glove should be evaluated with CE-mark with pictogram (symbol) showing the protection against risk, e.g., chemicals , microorganisms, heat as well as other mechanical risks.

\section{REFERENCES}

[1] Mellström GA, Boman AS. Gloves: types, materials, and manufacturing. In: Mellström
GA, Wahlberg JE, Maibach HI (eds) Protective gloves for occupational use. CRC Press, Boca Raton, FL, 1994; pp 21-35

[2] Zinner NL. How safe are your gloves? A study of protective barrier properties of gloves. Journal of the Association of Perioperative Registered Nurses 1994; 59: 879-82.

[3] Muto CA, Sistrom MG, Strain BA. Glove leak agerates as a function of latex content and brand caveatemptor. Arch Surg 2000; 135 : 982-5.

[4] Phalen RN, Que Hee SS, Xu W. Acrylonitrile content as a predictor of the captan permeation resistance ford disposable nitrile rubber gloves. Journal of Applied Polymer Science 2007; 103:2057-63.

[5] Phalen RN, Wong WK. Tensile properties and integrity of clean room and low-modulus disposable nitrile gloves: a comparison of two dissimilar glove types. Annals of Occupational Hygiene 2012; 56(4): 450-7.

[6] Health and Safety International, EU Glove Regulations, 2012. Available from: ww.hsimagazine.com/article/ eu.gloveregulations-743. 